\title{
PRELIMINARY RESULTS RELATED TO HUMAN FACTORS ENGINEERING SPECIFICATIONS FOR ADVANCING RADIATION DETECTION EQUIPMENT'S
}

\author{
Kozeta Tushe $^{1 *}$, Dritan Prifti ${ }^{1}$, Charles Massey ${ }^{2}$, Elida Bylyku ${ }^{1}$, Brunilda Daci ${ }^{1}$ \\ I*Institute of Applied Nuclear Physics, Street "Thoma Filipeu” Qesarakë, P.O Box 85, Tirana, Albania; \\ ${ }^{2}$ International Atomic Energy Agency, Vienna International Centre, PO Box 100, 1400 Vienna, Austria; \\ "Corresponding Author Kozeta Tushe, e-mail: kozeta.bode@ fshn.edu.al;
}

Received November 2020; Accepted December 2020; Published January 2021;

DOI: https://doi.org/10.31407/ijees11.106

\begin{abstract}
The current state of portable and handheld radiation detection instruments and systems used to detect a criminal or an unauthorized act with nuclear security implications involving nuclear or other radioactive material that is out of regulatory control is often inadequate to meet the nuclear security needs of the users within States. This work thoroughly supported by IAEA, chiefly from Division of Nuclear Security, Department of Nuclear Safety and Security. Incorporating human factors early in design is a cost-effective approach to minimizing human error during operational use. Mitigating human error for an established system is more difficult than factoring in human capabilities and limitations in initial design. In some cases, performance (detection sensitivity, battery life, etc.) of the instrument has been sacrificed to reduce weight. Equipment design should be assessed from a human interface perspective to help design engineers to create a better product. This paper provides some of the preliminary results of the research experiments studying the form and weight factors of different radiation detection equipment's. So far are performed about 1000 experiments, mainly students (above 18 years old) and also costumes staff are involved. Experiments were also conducted simulating different weather (winter/summer) and field conditions for determining optimal equipment specifications. All the above described research activities have been done under the Coordinated Research Project (CRP) J02012 "Advancing Radiation Detection Equipment for Detecting Nuclear and Other Radioactive Material out of Regulatory Control" organized by International Atomic Energy Agency (IAEA). Albania has joined this CRP in 2017 and since then the Institute of Applied Nuclear Physics has been collecting data from a large number of research experiments examining different form factors and weights of radiation detection equipment under various use conditions.
\end{abstract}

Keywords: handheld radiation detection, weight factors, form factors, Equipment design 